\title{
Promoção da cultura na cidade marginal: desenvolvimento humano na comunidade Sol Nascente (DF)
}

As necessidades básicas da população relacionadas ao desenvolvimento intelectual em espaços periféricos necessitam uma atenção maior em relação a sua apropriação por parte da comunidade, proporcionando maior eficiência das Políticas Públicas. A presente pesquisa tem por objetivo desenvolver um anteprojeto arquitetônico que promova cultura, educação, lazer e desporto orientado por expressões artísticas locais na comunidade de Sol Nascente (DF). Na metodologia da pesquisa foram utilizados, estudo bibliográfico, aspectos socioeconômicos, dados históricos, dados populacionais, fragilidades regionais, climatologia e geografia além dos estudos de caso investigados em propostas semelhantes localizas em grandes centros. 0 estudo bibliográfico demonstrou o quanto à implantação de equipamentos públicos, sobretudo os educacionais, em regiões periféricas aprimora o desenvolvimento humano em diversos aspectos, além de levar a periferia mais oportunidades para a população e reduzir as taxas de criminalidade. Por consequência disso, melhorar os índices locais como, educação, renda, saúde e saneamento básico, reduzindo ou eliminando os da pobreza e extrema pobreza, promovendo o exercício da cidadania com garantia do direito à cidade.

Palavras-chave: Desenvolvimento humano; Projeto de arquitetura; Comunidade Sol Nascente; Anteprojeto arquitetônico.

\section{Promotion of culture in the marginal city: human development in the Sol Nascente community (DF)}

The basic needs of the population related to intellectual development in peripheral spaces need greater attention in relation to their appropriation by the community, providing greater efficiency in Public Policies. This research aims to develop an architectural project that promotes culture, education, leisure and sport guided by local artistic expressions in the community of Sol Nascente (DF). In the research methodology, bibliographic study, socioeconomic aspects, historical data, population data, regional weaknesses, climatology and geography were used, as well as case studies investigated in similar proposals located in large centers. The bibliographic study showed how the implementation of public facilities, especially educational ones, in peripheral regions improves human development in several aspects, in addition to bringing more opportunities to the periphery for the population and reducing crime rates. As a result, improve local indexes such as education, income, health and basic sanitation, reducing or eliminating those related to poverty and extreme poverty, promoting the exercise of citizenship with a guarantee of the right to the city.

Keywords: Human development; Architectural design; Rising Sun Community; Architectural draft.

Topic: Arquitetura e Urbanismo

Reviewed anonymously in the process of blind peer
Received: 10/10/2019

Approved: 21/03/2021

Diogo Rafael do Nascimento (D)

Universidade do Oeste de Santa Catarina, Brasil

http://lattes.cnpq.br/9013441670449640

http://orcid.org/0000-0002-3254-6062

diogorafael2@hotmail.com

\section{Elizandra lop}

Universidade do Oeste de Santa Catarina, Brasil

http://lattes.cnpq.br/6535008268762855

http://orcid.org/0000-0002-1434-8361

elizandra.iop@unoesc.edu.br

Anderson Saccol Ferreira (iD

Universidade do Oeste de Santa Catarina, Brasil

http://lattes.cnpq.br/4850843904897537

http://orcid.org/0000-0002-6237-9912

anderson.ferreira@unoesc.edu.br

d

DOI: 10.6008/CBPC2674-6425.2021.001.0001
Referencing this:

NASCIMENTO, D. R.; IOP, E.; FERREIRA, A. S.. Promoção da cultura na cidade marginal: desenvolvimento humano na comunidade Sol Nascente (DF). Technology Science, v.3, n.1, p.1-11, 2021. DOI: http://doi.org/10.6008/CBPC2674-6425.2021.001.0001 


\section{INTRODUÇÃO}

No Brasil, o fenômeno da urbanização se deu por conta da migração interna vista pela abolição da escravatura, e pela imigração europeia, que fez com que as cidades brasileiras, principalmente Rio de Janeiro, vivesse um período de superlotação sem oferecer o mínimo de condições urbanas (DUMONT, 2014). As primeiras aglomerações brasileiras que foram consideradas favelas, surgiram no final do século XIX, na cidade do Rio de Janeiro, onde até então, as habitações populares eram denominadas cortiços, estalagens ou casas de cômodos, localizadas nas regiões centrais da cidade, próximo ao local de trabalho do proletariado (QUEIROZ FILHO, 2011).

No caso da cidade de Brasília sua urbanização ocorre devido a sua construção na década de 1950, que leva milhares de pessoas do Brasil todo em busca de trabalho até ela. Após sua construção, aquelas pessoas acabam por permanecer na região, mas ao redor da cidade de Brasília, dando origem às cidades satélites. As populações de baixa renda no entorno do grande centro urbano foram afastadas para aglomerados criados para esse fim.

A atual pesquisa está inserida na linha de projeto arquitetônico e projeto de urbanismo, e busca demonstrar a importância de promover cultura em espaços urbanos marginalizados. Nesse contexto, surge a seguinte questão de pesquisa: De que forma a arquitetura pode auxiliar na melhoria de vida da população carente, que vive em espaços periféricos?

O objetivo geral da pesquisa é desenvolver um anteprojeto arquitetônico que promova cultura, educação e lazer, orientado por expressões artísticas locais na comunidade de Sol Nascente (DF). Os objetivos específicos compreendem: a) realizar estudos de caso que contribuam com a elaboração da proposta arquitetônica; b) desenvolver o anteprojeto arquitetônico adequado às necessidades da população.

Adotamos como procedimento metodológico para o desenvolvimento da pesquisa a pesquisa Aplicada de caráter Qualitativa, que compreenderá: a) Estudo dos aspectos socioeconômicos da região, história da comunidade, número de habitantes, principais fragilidades; b) estudo de aspectos climáticos, relevo e entorno; c) estudos de caso sobre outras arquiteturas do gênero que obtiveram efetivo sucesso em suas edificações; d) desenvolvimento do conceito e partido arquitetônico; e) idealizar o anteprojeto arquitetônico.

A elaboração da proposta arquitetônica, assim como o estudo do programa de necessidade e prédimensionamento buscou uma arquitetura que promova integração e atenda às necessidades da população do local. O projeto de arquitetura procurou atingir de forma eficiente os objetivos da pesquisa, embasando a elaboração do anteprojeto. Além dessa introdução o artigo apresenta a revisão teórica, com uma literatura que promove a construção da proposta arquitetônica. Na sequência o método, que descreve em síntese a forma para elaboração da pesquisa e do projeto de arquitetura. Por fim, os resultados que delineiam as formas acertado dos anseios arquitetônicos do projeto. 


\section{REVISÃO TEÓRICA}

Na década de 1950 é lançado o Plano de Metas do novo presidente, Jucelino Kubitschek, com o compromisso de construir Brasília e mudar a Capital para o interior (PEREIRA et al., 2018). A mão de obra para a construção da nova capital foi provinda de operários da construção civil, peões de obra, trabalhadores braçais, de baixa qualificação profissional, a maioria deles com pouca escolaridade, às vezes analfabetos, eram conhecidos como "candangos", a maioria deles migrando do Nordeste em busca de melhores condições de vida (LUIZ et al., 2010).

Após a fundação da nova capital, JK foi exilado, e o novo presidente suspendeu inúmeras obras, gerando uma grande onda de desempregos na capital (LUIZ et al., 2010). Essa onda fez surgir diversos aglomerados de favelas próximas ao Plano Piloto, o que causou desconforto às autoridades. Em apenas nove anos de inaugurada, Brasília já possuía cerca de 80 mil favelados, dividindo o espaço de 15 mil barracos, foi então, que em 1969 o problema da favelização foi considerado o problema mais grave da cidade, considerado um problema social. Naquele momento, os candangos foram removidos para assentamentos desprovidos de infraestrutura básica, e foi o começo das cidades satélites que foram criadas sucessivamente ao longo dos anos.

O Setor Habitacional Sol Nascente (SHSN) teve sua origem no loteamento das chácaras limítrofes à Região Administrativa de Ceilândia, cuja urbanização nos bairros não foi orientada por um plano urbano com infraestrutura básica instalada, nem especificações urbanísticas, como dimensões das ruas, dos lotes, dos equipamentos de lazer e esporte. Atualmente é considerado uma favela e apresenta várias deficiências em serviços e condições urbanas para funcionamento e habitabilidade (NEGRET, 2017). O local sofre com graves problemas de saneamento, saúde e segurança. Souza (2018) define que:

A ação dos grileiros, gangues e as 'derrubadas' por parte do Governo trazem à população um climatério de insegurança e apreensão, fazendo com que os habitantes não se sintam parte da cidade e, consequentemente, não auxiliem em sua construção ideológica. (SOUZA, 2018)

Em relação aos espaços e equipamentos públicos, o SHSN é extremamente carente, não dispondo de ambientes adequados para lazer e esportes, contando com apenas duas quadras para futebol com grama sintética (NEGRET, 2017). A localização dessas quadras não são zonas seguras e a população geralmente utiliza os equipamentos da Região Administrativa vizinha, Ceilândia. Além disso, a população não dispõe de parques nem áreas verdes para seu conforto urbano (NEGRET, 2017). A primeira escola do SHSN foi inaugurada em fev. 2020, trata-se de uma estrutura com $4.550 \mathrm{~m}^{2}$ que abriga salas de aula, uma quadra coberta, cozinha experimental, laboratórios de arte e ciências, sala de música, teatro de arena, quadra poliesportiva e laboratório de informática. A escola atenderá os alunos de ensino infantil e fundamental, com a expectativa de atender até 950 estudantes (MACHADO, 2020).

O SHSN necessita de forma urgente de políticas públicas de promoção da dignidade e bem-estar à população local, tratar de melhorias como saneamento básico de qualidade e para todos, equipamentos urbanos que supram às necessidades dos moradores e desenvolvimento humano através da cultura, da educação e do desporto. $O$ estudo de caso em arquitetura e urbanismo trata de analisar criteriosamente uma 
obra já consolidada com a finalidade de aprimorar o projeto arquitetônico a desenvolver. A partir disso averiguar em que aspectos a obra obteve sucesso ou fracasso para a tomada de decisões projetuais. A pesquisa aborda estudos de caso dos Centros Educacionais Unificados (CEU) e o caso de intervenções urbanas em Medellín (CO).

O programa de necessidades dos primeiros 45 Centros Educacionais Unificados (CEUs) implantados na capital de São Paulo seguia algumas diretrizes padrões com possibilidade de mudanças em itens específicos conforme a necessidade de cada terreno, cada unidade possui uma área com cerca de 13 mil metros quadrados construídos, abrigando equipamentos como: a) Centro de Educação Infantil (CEI); b) Escola Municipal de Educação Infantil (EMEI); c) Escola Municipal de Educação Fundamental (EMEF); d) Conjunto esportivo; e) Conjunto cultural; f) Centro comunitário; g) Telecentro (CANGUSSÚ, 2010). O projeto concebido pela equipe de projetos da Prefeitura de São Paulo (EDIF) agrupa o programa de necessidades em três conjuntos volumétricos de formas simples e despojadas na Figura 1.

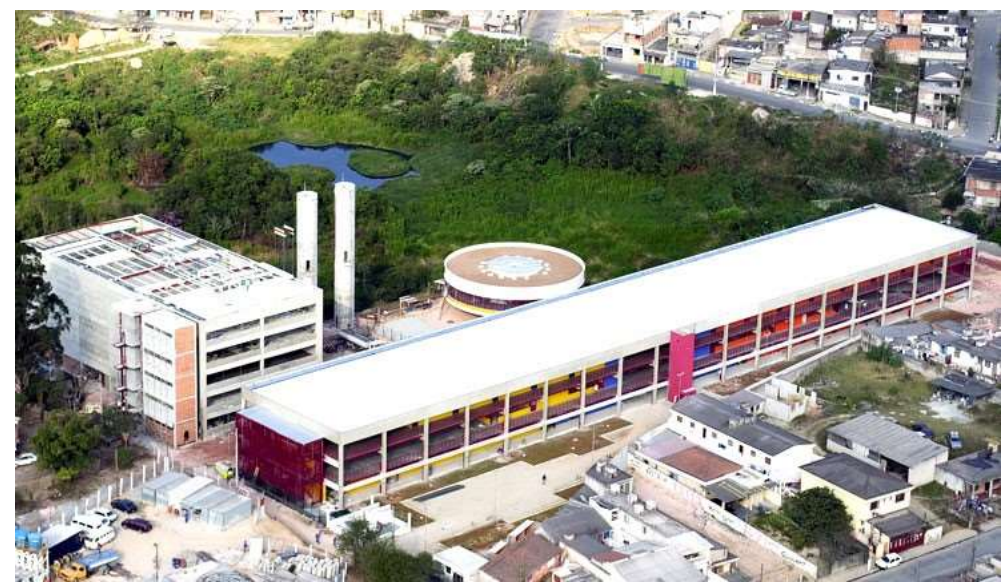

Figura 1: CEU Três Lagos. Fonte: Prefeitura de São Paulo (2019).

O maior em forma ortogonal abriga as salas de aula, refeitórios, biblioteca, programa de inclusão digital, padaria-escola, áreas para exposições e convivência. O menor, em forma de disco elevado do solo, abriga a creche. 0 último em formato retangular, recebe o teatro, ginásio esportivo com piso flutuante e sala de ensaios musicais. A estrutura foi desenvolvida em sistemas de pré-moldados garantindo agilidade na construção.

Cangussú (2010), conclui em sua pesquisa que o CEU é "uma iniciativa inovadora e com conceituação filosófica e social adequada à ideia de cidade educadora. Seu projeto atende aos objetivos mais amplos de inclusão social e diminuição das diferenças sociais" (CANGUSSÚ, 2010). Possui um modelo de gestão democrática, localização dos edifícios sempre conforme o mapa da exclusão social e arquitetura moderna agregando valor aos processos educativos. Consegue reunir todos os seus equipamentos urbanos em um único espaço, atendendo integralmente as populações de regiões periféricas. Entretanto, é vulnerável às mudanças de governo, e sua sustentabilidade e continuidade dependem de ações coletivas da sociedade e ações pontuais do poder público (CANGUSSÚ, 2010). Nesse contexto, o CEU fica inserido no núcleo da carência de equipamentos públicos, levando a mão do estado às localidades antes controladas majoritariamente por grupos criminosos, auxiliando na redução da criminalidade através da educação e da 
cultura.

Posteriormente à construção dos primeiros CEUs em São Paulo (SP), iniciou-se a implantação de um novo projeto em Medellin (Colômbia) entre 2004 e 2008, semelhante ao dos CEUs brasileiros (SILVA, 2017). Medellín já foi considerada a cidade mais violenta do mundo nos anos de 1990, com índice de homicídios por cada cem mil habitantes na casa dos 380, número que chegou a 19 casos por cada cem mil habitantes em 2016 (VELOSO et al., 2018). No período de enfrentamento, o orçamento municipal de cultura foi ampliado de $0,68 \%$ para $5 \%$, enquanto o percentual da educação passou de $12 \%$ para $40 \%$, utilizados para a implantação dos complexos desportivos, instituições escolares e os Parques Bibliotecas, objetivando a melhoria de vida e inclusão social de populações hipossuficientes que é fatalmente prejudicada pela ausência do estado. Dessa forma, a população carente teve acesso à estrutura de lazer, educação cultura e inclusão social, o que reduziu eficientemente os índices de criminalidade (VELOSO et al., 2018).

Condigno com essa inserção de educação, cultura e arte, Medellín transformou-se em Cidade Educadora, nos espaços públicos os usuários são convidados a sentirem os diferentes tipos de superfícies e brincarem nos espelhos d'água, a cidade revitalizou seu tecido urbano e paisagem, hoje é uma cidade que se abre à vivência urbana e apresenta ao mundo uma imagem arquitetônica, social e cultural renovada (DIAS; ESTEVES JUNIOR, 2017. Da mesma forma que em São Paulo (SP), a escolha dos terrenos para implantação dos Parques Bibliotecas foi definida pelos níveis de pobreza, violência ou desenvolvimento humano, optando-se por fronteiras entre comunidade e grupos inimigos, ou ainda em espaços onde o trânsito de pessoas era complicado e a violência, bastante evidente (SOARES, 2013). A implementação dos Parques Bibliotecas exige amplo estudo do território e da participação da população, avaliando as particularidades que cada Parque deve atender (SOARES, 2013).

\section{METODOLOGIA}

De forma a atender os objetivos da pesquisa, adotamos como procedimento metodológico cinco aspectos para construção e elaboração do projeto de arquitetura. A área de estudo para a implantação do empreendimento localiza-se no Distrito Federal do Brasil, situado na Região Administrativa de Sol Nascente/Pôr do Sol, fazendo divisa direta com a Região Administrativa da Ceilândia. A Figura 1 ilustra e esquematiza a região de implantação.

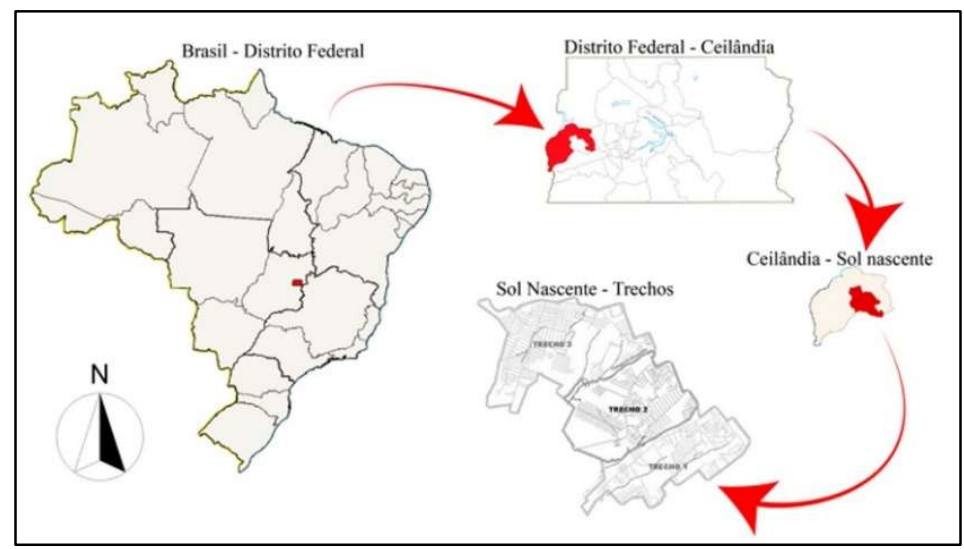

Mapa 1: Área de inserção urbana. Fonte: IBGE (2010). 
No primeiro momento analisou-se os aspectos socioeconômicos da região, a história da comunidade inserida, número de habitantes do município e as principais fragilidades do local. Na sequência foram realizados dois estudos de caso referente a arquitetura do CEU Pimentas - Guarulhos (SP) e da Escola Santo Domingo Savio - Medellín (Colômbia). Nesse estudo, analisou-se a relação interior, exterior, análise estrutural, elementos construtivos, embasamento, corpo, coroamento e análise bioclimática.

A elaboração da proposta arquitetônica segue o Quadro 1 demonstrando a síntese para elaboração da proposta de arquitetura.

Quadro 1: Síntese metodológica para proposta arquitetônica.

\begin{tabular}{|l|l|l|}
\hline Aspectos socioeconômicos & $\begin{array}{l}\text { Comunidade e inserção urbana. Aspectos regionais e } \\
\text { municipais. Indicadores de sustentabilidade }\end{array}$ & $\begin{array}{l}\text { Fragilidades. } \\
\text { Pontos positivos e negativos. } \\
\text { Fluxos. Viabilidade. }\end{array}$ \\
\hline Estudo de caso & Aspectos construtivos, relação interior e exterior. & Análise física e ambiental \\
\hline Análise projetual & $\begin{array}{l}\text { Pré-dimensionamento } \\
\text { Programa de necessidades }\end{array}$ & $\begin{array}{l}\text { Estudo da forma e volumetria. } \\
\text { Partido e conceito arquitetônico }\end{array}$ \\
\hline $\begin{array}{l}\text { Elaboração anteprojeto de } \\
\text { arquitetura }\end{array}$ & Planta baixa e implantação & $\begin{array}{l}\text { Cortes, fachadas e maquete } \\
\text { eletrônica }\end{array}$ \\
\hline
\end{tabular}

Por fim o projeto de arquitetura que pode ser considerado a alma da edificação. Nele são articuladas propostas e soluções para uma obra. O projeto é muito mais que apenas o desenho, pois inclui levantamento de dados e informações da análise projetual e das condicionantes legais para saber o que é possível construir naquela área. Após essa análise, é então elaborado o conceito, onde são moldadas as intenções do arquiteto.

O campo do projeto arquitetônico situa-se entre ciência e arte, permitindo múltiplas abordagens. Estudos do processo criativo indicam cinco tipos de heurísticas aplicadas na solução de projetos, que são: analogias antropométricas; analogias literais; relações ambientais; tipologias pré-definidas e linguagens formais. Portanto o processo de projeto é considerado um conjunto de atividades intelectuais, tais como análise, síntese, previsão, avaliação e decisão (KOWALTOWSKI et al., 2006). O processo do projeto não é uma sequência de atividades exatas, já que o projetista não possui a priori amplo conhecimento da natureza do objeto de projeto, portanto o processo de pensamento não deve ser considerado totalmente racional (KOWALTOWSKI et al., 2006).

\section{RESULTADOS E DISCUSSÃO}

A área de estudo para a implantação do empreendimento localiza-se no Distrito Federal do Brasil, situado na Região Administrativa de Sol Nascente/Pôr do Sol, fazendo divisa direta com a Região Administrativa da Ceilândia. Durante os anos de 1990, o território do Sol Nascente, até então uma área rural, iniciou um processo de urbanização. O SHSN começou a se formar com pessoas em busca de moradia barata, havendo grande oferta de lotes viabilizados ilegalmente por grileiros de terra (GALVÃO, 2018). No início dos anos 2000 a área foi batizada de Sol Nascente. Era uma invasão se formando no meio do mato nos confins da Ceilândia, a maior cidade-satélite de Brasília, com altos índices de violência. Nessa época só havia luz de vela e a água deveria ser buscada em outros locais, além de não haver transporte público, já que as empresas de transporte alegavam não haver público justificável para uma nova linha, onde menos de 20 anos depois, passou a ocupar o posto da segunda maior favela do Brasil. 
Localizada a apenas 35 quilômetros do Palácio do Planalto e do Congresso Nacional, a favela horizontal em solo plano não para de crescer. Mesmo que haja fiscalização por parte do governo do Distrito Federal (DF), que já fez várias derrubadas de casas e barracos, o SHSN vai se espalhando para além do tamanho oficial. Estima-se que hoje cerca de 100 mil pessoas habitem a área. Essas pessoas, apesar da proximidade com o poder, em geral só circulam nos palácios, prédios tombados e quadras planejadas prestando serviços de baixa qualificação.

Desde que a ocupação foi reconhecida como setor habitacional, em 2008, pela Lei Complementar no 785, começou um processo de urbanização na entrada do bairro e nas vias principais, apresentando um cenário diferente de 10 anos atrás, onde o asfalto passou a cortar diversas ruas e o comércio local ganhou força, além disso o Governo do Distrito Federal (GDF) regularizou algumas áreas e entregou 344 escrituras em 2018, e também implantou uma Unidade de Saúde Básica (USB) no mesmo ano. Apesar das melhorias, ainda há um grande contraste de diferenças, pois não é preciso andar muito para encontrar ruas em condições precárias, quanto mais longe do centro, pior é a situação para os moradores (GALVÃO, 2018).

O terreno para implantação trata-se de um lote plano, típico da maior parte do relevo do Planalto Central. Inserido em meio a uma área residencial, na quadra 202, área especial 01, em uma Zona Urbana de Expansão e Qualificação, dentro da Área de Regularização de Interesse Social (ARIS). O terreno passou por uma vistoria em março de 2019 elaborada pela Companhia imobiliária de Brasília (Terracap), gentilmente cedida via e-mail, onde foi solicitada pela Secretaria do Estado de Educação do Distrito Federal, demonstrando interesse em edificar um equipamento social de caráter educacional. $O$ terreno possui vegetação predominantemente rasteira, exceto na área do parque, possibilitando a construção com menor impacto ambiental. Suas delimitações seguem um desenho informal, apresentando cotas de diferentes dimensões em cada uma de suas extremidades, totalizando uma área de 25.657 metros quadrados.

Esse lote fica próximo de alguns setores da RA, como a Chácara 96, a mais próxima do empreendimento. Nessa região os condomínios do setor possuem ruas amplas e regulares, porém sem pavimentação. O endereçamento local não apresenta dificuldades de localização e possui conjuntos alfabéticos e numerações de unidades (GODOY, 2013). Com o intervalo de um quarteirão aos fundos da edificação em estudo, fica localizado o setor das QCS que é considerado o mais confuso do Trecho 2 . Nele encontramos endereçamento confuso, lotes sem dimensões definidas, muitas áreas de risco, esgoto à céu aberto, grande quantidade de lixo nas ruas, vias irregulares e de difícil acesso, sem pavimentação, encontrase muitos becos e vielas, contém unidades com vários endereços diferentes, possui alto índice de violência, ocorrem enchentes na área e vários condomínios são fechados sem acesso (GODOY, 2013).

A implantação da edificação no terreno respeitará todas as questões legais, ambientais e sociais com o intuito de oferecer o máximo de impactos positivos na vida da população com o mínimo de impactos negativos, sobretudo os ambientais, por tratar-se de uma região repleta de fragilidades em seu solo.

Devido ao característico clima seco, a amplitude térmica da cidade de Brasília, onde a mínima (noturna) é de $15,4^{\circ}$ e a máxima (diurna) de 30,70 , sugere que a arquitetura nesses climas secos e quentes deveria possibilitar, durante o dia, temperaturas internas abaixo das externas, e o oposto durante a noite. 
Nesse caso a ventilação não seria útil, pois o ar externo estaria sempre em uma temperatura mais fria ou mais quente do que o ar interno. Desse modo podem-se adotar partidos arquitetônicos que tenham uma inércia elevada, a qual acarretará em um atraso significativo no número de horas que esse calor levará para atravessar as vedações da edificação. Outro fator a considerar é o tamanho das aberturas, pois não há conveniência de ventilação, permitindo tamanhos reduzidos, destinados a iluminação. Assim, menores superfícies ficarão expostas aos efeitos da radiação transmitida pelo vento, o qual em clima seco traz consigo poeira em suspensão, prejudicial à saúde (FROTA et al., 2007).

Os espaços abertos nesses climas podem conter espelhos d'água, chafarizes ou outras soluções semelhantes. A umidificação gerada por essas águas proporcionará maior conforto aos usuários, já que o uso da água como elemento de alteração de microclimas também pode ser incorporado às construções, principalmente em pátios internos. É possível criar condições microclimáticas bastante agradáveis nesses espaços, já que a maior umidade do ar resultará também em melhores condições térmicas (FROTA et al., 2007).

O empreendimento em estudo trata-se de uma intervenção urbana institucional de grandes proporções, procurando atender às carências da população em relação a equipamentos urbanos, oferecendo recursos como educação infantil, educação básica e atividades para a comunidade em geral divididas entre culturais, esportivas e de lazer. O público alvo do empreendimento são todos os moradores da Região Administrativa de Sol Nascente (DF), principalmente do Trecho 2, por estar localizado em seu núcleo. Estimase a necessidade de 115 funcionários trabalhando em 2 turnos, sendo 60 professores, 10 profissionais de limpeza, 10 da área administrativa, 6 da segurança, 4 da saúde, 8 da assistência social, 15 das cozinhas e refeitórios e 2 dos cuidados com o paisagismo e limpeza das praças.

Estima-se que a proposta provoque impactos positivos na vida dos moradores, que poderão usufruir de diversos equipamentos de qualidade os quais a região é carente, e que assim possam lutar em busca de mais soluções que urbanizam e dignificam a sociedade da localidade. Além disso, espera-se que uma intervenção arquitetônica possa influenciar nas características das edificações próximas, aumentando o desejo pelo zelo, embelezamento e cuidado com a aparência estética, funcionalidade e conforto térmico das casas, considerando assistência por parte do governo, de políticas públicas para habitação.

A proposta arquitetônica contempla a criação de uma intervenção junto à comunidade Sol Nascente, uma obra de grande porte e cunho institucional, contemplando espaços educativos, culturais, desportivos e de lazer, buscando promover desenvolvimento humano e dignidade à população carente de equipamentos públicos. O espaço terá fachada para a avenida principal, e contornado por áreas residenciais, ocupando uma quadra. É desejável que essa área não seja obstruída por gradis em nenhuma de suas faces, permitindo que esteja integrada ao bairro.

O conceito dessa proposta arquitetônica estima a apropriação do espaço pela população local, que possibilite que sintam como parte de seus lares, encontrando atividades que tragam melhoria na saúde e no intelecto, auxiliando na garantia devida pelo Estado dos princípios constitucionais da ordem social. Através disso, pretende-se promover a dignidade humana, possibilitando acessos para todos. A cultura local, será 
representada pela Capoeira, através de seus instrumentos, sobretudo o Atabaque. A representatividade ainda se dará por conta do nome sugerido à instituição, intitulado Centro Educacional e Esportivo Palmares (CEEP).

Em relação ao partido, pretende-se manter a maior parte dos materiais aparentes, concreto, tijolo e aço. Assim como são as residências locais, buscando apropriação, algo que os pertença. Será desenvolvida uma parede inteiramente envidraçada com vidros tipo U-Glass, provocando a sensação de movimento. Esses elementos serão iluminados através de led's com cores variadas, despertando curiosidade, alegria, momentos para selfies, com a intenção de trazer, em conjunto com os chafarizes do espelho d'água, bons momentos para os usuários. Os ambientes deverão ter circulações generosas, iluminadas e com qualidade no ar, garantindo a salubridade do espaço e a saúde dos usuários.

A pista de caminhada será disposta de forma orgânica, passando por diversos espaços do CEEP, inclusive pela área arborizada já existente na parte mais a leste do terreno. Na fachada principal, serão elaborados elementos que relembrem as cordas do atabaque, porém como um grande painel, revestindo o acesso principal como mostramos na Figuras 2.

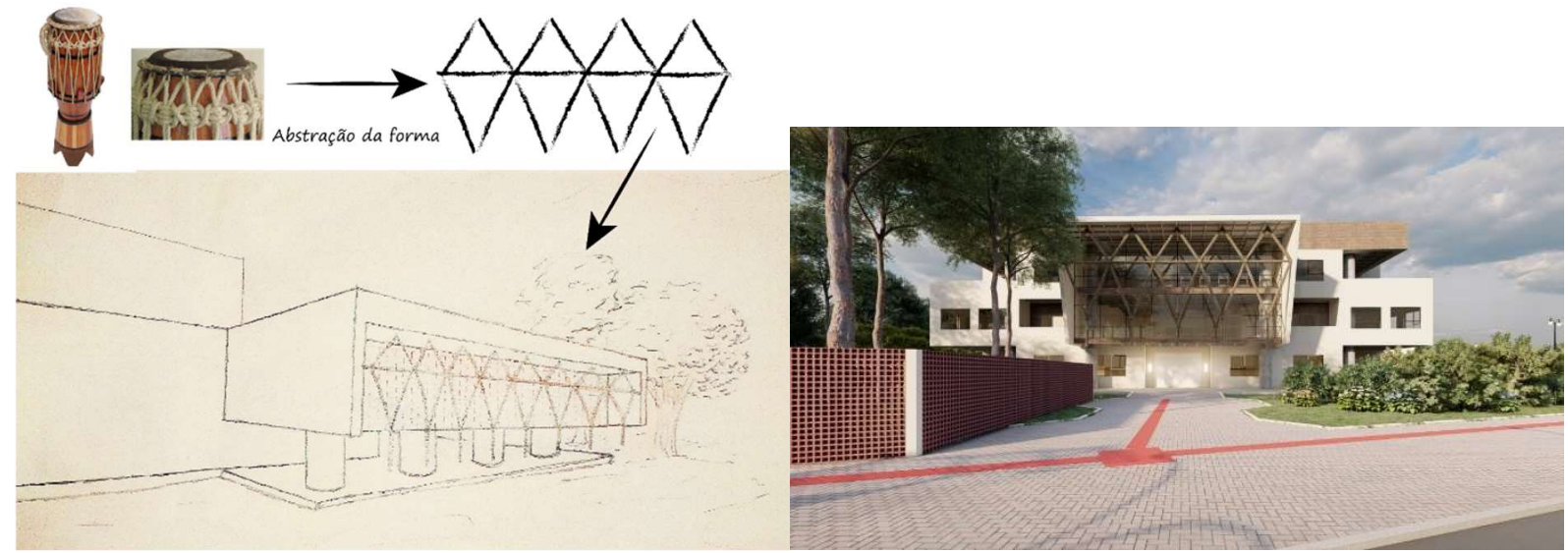

Figura 2: Proposta arquitetônica da fachada frontal do projeto de arquitetura.

Os principais materiais a serem aplicados, serão simples e encontrados facilmente nas proximidades. Será optado pelo uso de materiais de fácil manutenção, como as esquadrias em alumínio com pintura epóxi, evitando que haja deterioração por intempéries. As paredes serão em concreto aparente, tijolos de barro maciços em alguns detalhes e painéis de gesso em determinadas divisões de ambientes, oferecendo redução de cargas na estrutura. As lajes serão do tipo nervurada com cubetas, e os pilares em concreto armado circular moldados in loco. Em uma chamada mais artística, com o uso de cores, haverá uma parede de forma orgânica onde serão utilizados vidros estruturais tipo " $\mathrm{C}$ " demonstrado na Figura 3.

Os pisos no andar térreo serão em concreto polido com acabamento acetinado, enquanto nos andares superiores será utilizado porcelanato amadeirado, buscando aconchego, principalmente nos ambientes escolares. A cobertura será sustentada com estrutura metálica de treliças e telhas metálicas duplas com preenchimento em poliisocianurato (PIR).

As instalações elétricas, hidráulicas, de prevenção contra incêndio e telecomunicações ficarão sobrepostas nas paredes e tetos, com tubulações específicas confeccionadas em tubos de aço galvanizado e 
identificadas com a cor correspondente. As luminárias deverão utilizar lâmpadas em LED corretamente dimensionadas para cada ambiente e uso específico. As áreas molhadas receberão revestimento cerâmico do tipo grês liso esmaltado resistente à abrasão e ao manchamento, no piso e nas paredes até a altura do teto, afixadas com argamassa de alto desempenho. O sistema de ar condicionado será do tipo água gelada com estação central e ventiladores aparentes, afixados no teto. Em alguns pontos do forro serão distribuídos domos para captação da luz solar, trazendo economia de energia com iluminação artificial.

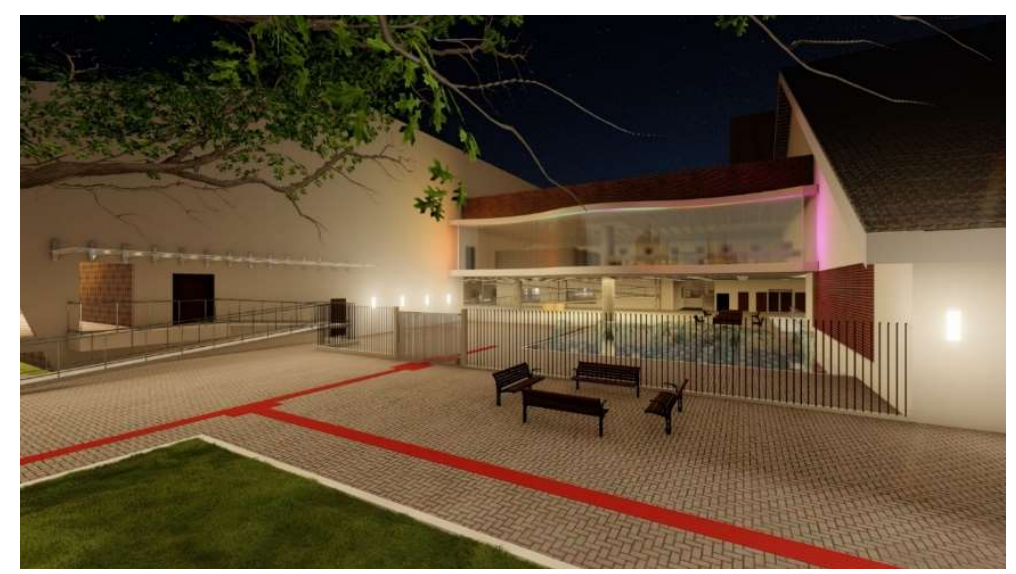

Figura 3: Fachada do projeto de arquitetura com vidro estrutural tipo "C".

A biblioteca deverá ser revestida com argamassa de cimento com Vermiculita Expandida para melhorar o conforto acústico, enquanto no auditório, com o mesmo propósito, serão planejados elementos em madeira para melhor distribuição do som. As escolhas dos materiais levam em consideração uma série de itens que buscam reduzir ao máximo os posteriores custos de manutenção da edificação, podendo resistir melhor às mudanças de governo e aos cortes de verba.

\section{CONCLUSÕES}

A proposta arquitetônica busca atingir de forma eficiente os objetivos da pesquisa, embasando a elaboração do anteprojeto, o qual terá andamento e conclusão no segundo semestre de 2020. Propõe-se que a arquitetura seja o agente articulador entre o Estado e a população, que será também beneficiada por seus espaços e equipamentos, planejados para o melhor atendimento, lazer e conforto dos usuários, e além disso, auxilia no processo de urbanização enquanto intervenção arquitetônica e urbanística. Estima-se que ao alcançar os objetivos propostos, em conjunto com Políticas Públicas inclusivas de qualidade, o desenvolvimento humano na região vai evoluir consideravelmente e provocar consequentes melhorias no tecido urbano.

Os resultados da pesquisa podem ser úteis para os municípios que buscam desenvolvimento urbano com qualidade e planejamento, com equipamentos públicos distribuídos de maneira que promova acessos para todos os habitantes, melhorando os índices de crescimento municipal de maneira uniforme. No caso da capital federal, a correta distribuição desses subsídios para a população poderá ajudá-la a se tornar a "cidade da esperança", algo que já era lema nos anos 1950 durante a sua construção, tornando-se assim modelo para os grandes centros brasileiros. 0 estudo demonstra o quanto a educação pode transformar a vida de um 
povo, porém os problemas políticos por muitas vezes levam ao fracasso grandes propostas, freando o desenvolvimento da nação.

Durante a pesquisa da região de inserção, a maior dificuldade encontrada foi a distância, por não possibilitar a verificação in loco da área de implantação, porém com o auxílio da Companhia Imobiliária de Brasília (Terracap) foi possível verificar documentos importantes para análise, como os mapas e a vistoria do lote realizada em 2019.

Assim como o Sol Nascente, existem diversas comunidades nas mesmas condições no DF e no restante do país. Desse modo indica-se mais estudos no campo da arquitetura e urbanismo enquanto promotores da qualidade de vida urbana. Com a quantidade e qualidade de recursos e o potencial humano, vivemos em um país preparado para atingir os níveis internacionais de desenvolvimento humano, econômico e social, necessitando apenas de governantes que trabalhem unidos, dando continuidade aos projetos sociais e promovendo um Brasil para todos.

\section{REFERÊNCIAS}

CANGUSSÚ, L. C. P.. Centros Educacionais Unificados de São Paulo: Implementação e continuidade numa nova gestão política. São Paulo: Universidade Metodista de São Paulo, 2010.

DUMONT, T. V. R.. Uma análise da política urbana e habitacional no Brasil: a construção de uma ilusão. Áskesis, v.3, n.1, p.23-44, 2014.

FROTA, A. B.; SCHIFFER, S. R.. Manual de Conforto Térmico. 8 ed. Studio Nobel, 2007.

GALVÃO, W.. Moradores do Sol Nascente, em Ceilândia, contam como é morar na região. Brasília: Correio Braziliense, 2018.

GODOY, C. D.. Sol nascente: trecho 2: redesenho e requalificação urbana. Monografia (Bacharelado em Arquitetura e Urbanismo) - Universidade de Brasília, Brasília, 2013.

KOWALTOWSKI, D. C. C. K.; CELANI, M. G. C. C.; MOREIRA, D. C.; PINA, S. A. M. G.; RUSCHEL, R. C.; SILVA, V. G.; LABAKI, L. C.; PETRECHE, J. R. D.. Reflexão sobre metodologias de projeto arquitetônico. Ambiente Construído, Porto Alegre, v.6, n.2, p.07-19. 2006.

LUIZ, E. B.; KUYUMJIAN, M. M. M.. Candangos: Uma história de trabalho e exclusão. Tempos Históricos, Brasília, v.14, p.258-279, 2010.
MACHADO, M.. Escola Classe JK, no Sol Nascente atenderá a mais de $\mathbf{9 0 0}$ crianças. Brasília: Correio Braziliense, 2020.

NEGRET, F. F.. Problemática socioambiental das favelas Sol Nascente e Pôr do Sol no Distrito Federal - 2000/2015: ausências e precariedade no espaço de vida. DEMA, Goiânia, v.46, p.229-253, 2017.

PEREIRA, A. S. B.; AVENA, B. M.. Brasília: espaço urbano e segregação. Cenário, Brasília, v.6, p.101-109, 2018.

QUEIROZ FILHO, A. P.. Sobre as origens da favela. Revista Mercator, Fortaleza, v.10, n.23, p.33-48, 2011.

SILVA, A. B.. Rede de espaços públicos: as intervenções dos Parques-Bibliotecas no espaço informal de Medellín. São Carlos, 2017.

SOARES, P. P.. Arquitetura como projeto social: Os casos dos Centros de Educação Unificada (CEUs) em São Paulo, Brasil, e dos Parques Biliotecas em Medellín, Colômbia. São Paulo: Universidade Presbiteriana Mackenzie, 2013.

SOUZA, E.. Um plano educacional para um novo tempo: Anísio Teixeira e as escolas classe/escola parque de Brasília. Caderno Eletrônico de Ciências Sociais, Vitória, v.3, n.2, p.39-52, 2018.

VELOSO, R. C.; COSTA, M. J. F.. As lições de Medellín: Intervenções urbanísticas versus qualidade de vida versus redução da criminalidade. Revista Direito Mackenzie, v.12, n.2, p.1-23, 2018.

A CBPC - Companhia Brasileira de Produção Científica (CNPJ: 11.221.422/0001-03) detém os direitos materiais desta publicação. Os direitos referem-se à publicação do trabalho em qualquer parte do mundo, incluindo os direitos às renovações, expansões e disseminações da contribuição, bem como outros direitos subsidiários. Todos os trabalhos publicados eletronicamente poderão posteriormente ser publicados em coletâneas impressas sob coordenação da Sapientiae Publishing, da Companhia Brasileira de Produção Cientifica e seus parceiros autorizados. Os (as) autores (as) preservam os direitos autorais, mas não têm permissão para a publicação da contribuição em outro meio, impresso ou digital, em português ou em tradução. 